\title{
Space-science hopes rest on rocket test
}

\section{New launch vehicle could carry next generation of NASA's research probes.}

When the Falcon 9 rocket makes its inaugural test flight, expected later this month, it will carry with it NASA's hopes for a new generation of low-cost rockets to ferry cargo and people into space.

The rocket - touted as a possible saviour of human spaceflight - could also solve a serious problem facing the next generation of space probes. Satellites that observe Earth and nearby planets, as well as space telescopes able to look deep into the cosmos, are about to be hit by the retirement of the Delta II rocket, a workhorse that has launched $60 \%$ of NASA's science missions during the past decade.

Among NASA's stable of rockets, the Delta II is the right size for all but the most ambitious science missions, and at about $\$ 50$ million per rocket the price was right too - ten years ago. But since then, the cost of a Delta II launch has roughly doubled, making it unaffordable. The last science launch scheduled for the Delta II is in 2011, for GRAIL (Gravity Recovery and Interior Laboratory), a mission to study the Moon's core by mapping tiny variations in its weak gravitational field.

"We're almost reaching the stage of desperation for launch vehicles," says Jack Burns, a space scientist at the University of Colorado at Boulder and a member of NASA's science advisory committee. NASA science chief Edward Weiler adds, "If there is no replacement ever for the Delta II, that would take away a critical capability." He hopes that in three or four years the Falcon 9, developed by SpaceX of Hawthorne, California, will emerge as a low-cost replacement. "Very much hoping, I might add."

SpaceX unveiled its plans for Falcon 9 in 2005 , and a year later won NASA contracts worth $\$ 278$ million to develop rockets that

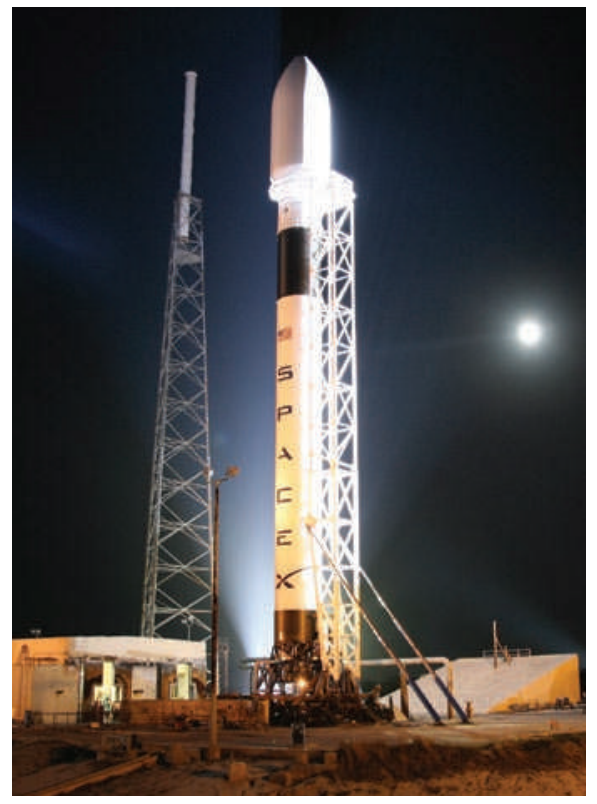

Countdown is imminent for the Falcon 9 rocket.

could carry supplies and science experiments to the International Space Station (ISS). In December 2008, SpaceX won a \$1.6-billion contract for 12 ISS resupply flights, up until the end of 2015. The rocket's potential role expanded in February, when President Barack Obama proposed axing the suite of NASA rockets intended to replace the Space Shuttle and once again send humans to the Moon. Some $\$ 6$ billion over 5 years - money that would have gone to the Constellation rockets - would instead be ploughed into commercial providers such as SpaceX, in the hope that they could transport not only cargo, but people as well (see Nature 463, 716-717; 2010).
This radical transition is still very much in $x$ doubt, as legislators in Congress fight to protect is space-industry jobs (see Nature doi:10.1038/ news.2010.189; 2010). Yet even the most ardent critics of Obama's new space vision are eager to see whether Falcon 9 can help to keep NASA astronauts in space.

In the obsession over human space flight, many are overlooking the role that the Falcon 9 could have in replacing the Delta II, which came to prominence during a golden era in the 1990s when rockets were plentiful and relatively inexpensive. The rocket's biggest buyer, the US Air Force, had to launch a constellation of global positioning satellites, and private satellite-communication companies such as Iridium were also snapping up the rockets by the handful.

But then the communications satellite market dried up, and the Air Force said it no longer had an essential need for the Delta II, conducting its final launch with one last year. Instead, the Air Force has committed to sustaining the very large Delta IV and Atlas V rockets in the Evolved Expendable Launch Vehicle programme.

\section{Price hikes}

As buyers have bailed, the price of a Delta II, including launch, has shot up. A decade ago, they were a relative bargain, ranging from $\$ 50$ million to $\$ 80$ million apiece. Now, each one costs about $\$ 120$ million - almost as expensive as the much bigger Atlas V - with further hikes expected. United Launch Alliance, the joint venture of Lockheed Martin and Boeing that makes the Delta II, would be happy to continue selling it to NASA. The components for five rockets are waiting to be assembled, says William Wrobel, who directs NASA's launch services programme. The problem is

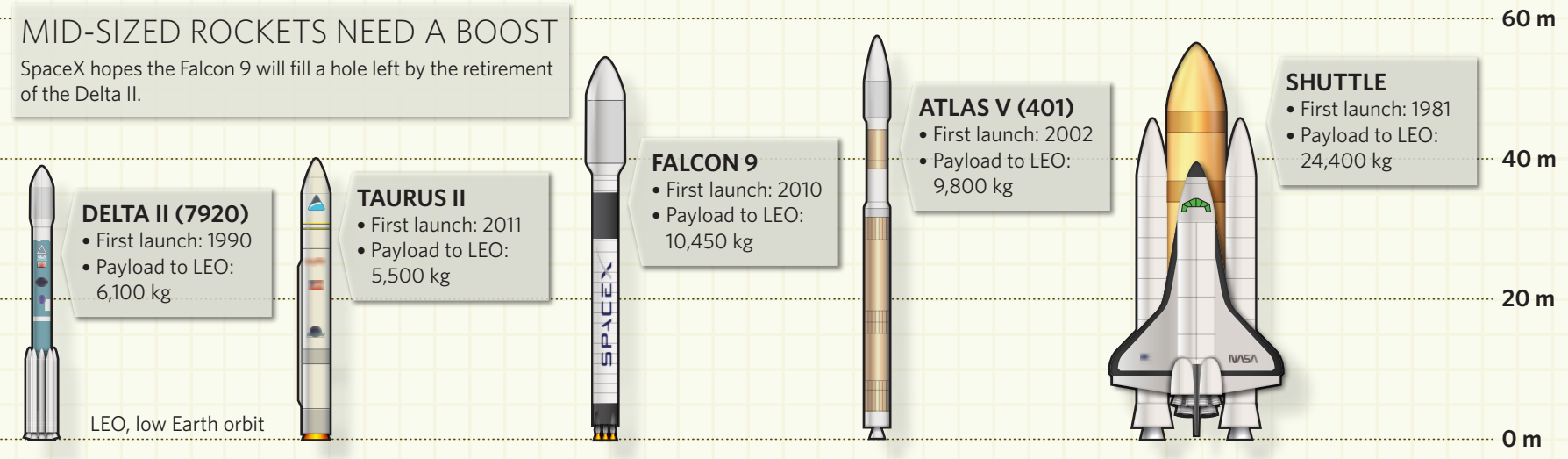


that, without the additional buyers and bigger market, NASA cannot afford to pay for the upkeep of the launch-pad infrastructure that the Air Force had paid for. "NASA can't go it alone," says Wrobel.

Wrobel says that most imminent mission launches, such as the 2011 launch of the heavy Mars Science Laboratory and Juno, a mission to Jupiter, needed the extra thrust of an Atlas V anyway. But if NASA officials are forced to buy more Atlas Vs in the future, they will be paying extra for unused launch capacity. "The more that the launch vehicle costs, the less science mission you get for your money. Or fewer missions," says Alan Stern, a planetary scientist at Southwest Research Institute in Boulder, NASA's former science chief and an advocate of commercial space flight.

Several missions could take advantage of Falcon 9's leaner launch capability and lower price of about $\$ 50$ million per launch. These include the Soil Moisture Active and Passive mission, an Earth-observing satellite due for launch in 2015; the International Lunar Network, a system of landers

$\begin{array}{ll}\text { "The more the } & \begin{array}{l}\text { designed to meas- } \\ \text { ure the Moon's seis- } \\ \text { mic activity, among } \\ \text { other things; and } \\ \text { launch vehicle }\end{array} \\ \begin{array}{ll}\text { costs, the less } & \text { modest-sized } \\ \text { science mission } & \text { astrophysics and } \\ \text { you get for youretary-science }\end{array} \\ \text { money." } & \begin{array}{l}\text { missions that would } \\ \text { launch in 2016. }\end{array}\end{array}$

All bets are not riding on the Falcon 9, however, which will launch from Cape Canaveral, Florida, and carry a prototype of its cargo capsule Dragon. Orbital Sciences, headquartered in Dulles, Virginia, and another winner of ISS cargo-transport money, is developing the Taurus II, another medium-sized launcher that is scheduled for first test flights in 2011 (see Mid-sized rockets need a boost). For the planned 2012 launch of the Lunar Atmosphere and Dust Environment Explorer (LADEE), Orbital is putting together stockpiled ballistic missiles into the Minotaur 5, which costs less than $\$ 50$ million and is just the right size for the small Moon mission.

If Falcon 9's test launch is successful, it should be carrying cargo to the ISS within a few months. But scientists will have to wait a while longer - before a new rocket can carry a scientific payload, NASA requires three successful launches and a technical certification that takes about three years. NASA hopes to certify Falcon 9 or one of its competitors by the end of 2013 .

Eric Hand

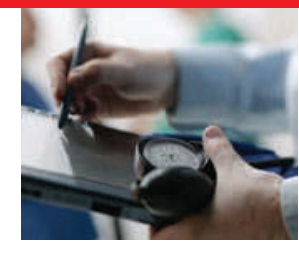

DOCTORS SEEK REFORM Cumbersome rules for UK clinical trials are driving research overseas. go.nature.com/q2q7BT

\section{Neglected diseases fund touted}

Despite decades of research into drugs and vaccines for neglected diseases such as tuberculosis and dengue fever, few products have made it through clinical development and into the hands of the millions who desperately need them.

One of the biggest hurdles is the sheer expense of running clinical trials, compared with the small profits that commercial companies can expect to make from treatments for diseases that disproportionately affect poor and marginalized populations.

This week, alongside the World Health Organization's (WHO's) annual assembly of health ministers in Geneva, Switzerland, a consortium of industry and nongovernmental organizations proposed a scheme to help address the problem: a global fund that would channel billions of dollars a year into product development.

Plans for the fund were put forward by the International AIDS Vaccine Initiative (IAVI), the pharmaceutical giant Novartis and the George Institute for International Health in Sydney, Australia. It would channel money from donors towards product-development partnerships (PDPs) - collaborative efforts between research agencies, donors and biotech and pharmaceutical companies to develop drugs, diagnostics and vaccines for the developing world. The fund aims to encourage contributions from donors who lack the resources or expertise to assess the quality and progress of the various PDP offerings.

Dozens of not-for-profit PDPs, including the IAVI, the Medicines for Malaria Venture, the Global Alliance for TB Drug Development, and the Drugs for Neglected Diseases initiative (DNDi), have been set up during the past 15 years. Their aim is to bridge the gap between basic research and product development, and to prevent promising research leads for neglected diseases from languishing on the shelf. They are run like businesses, but are supported by donor funding, and have generous intellectual-property rules to make any products affordable to poor countries, allowing generic manufacturers to make cheap versions freely.

PDPs have become an attractive choice for neglected-disease donors - of the estimated US $\$ 3$ billion spent on such research in 2008, about one-fifth was channelled through PDPs. Although only 13 of more than 1,000 drugs developed between 1975 and 1997 were for neglected diseases, PDPs created over the past decade already have 143 candidate products in development, and have rolled out 11 products for malaria, leishmaniasis and meningitis.

But many PDPs need a fresh cash injection as more of their product candidates begin to enter clinical development, the most expensive phase of drug and vaccine discovery. Without substantial new funding, projects will stall and waste much of the earlier development work and investments, says Paul Herrling, head of the Novartis Institutes for Developing World Medical Research.

The proposed PDP+ Fund would seek to raise funds from governments and other donors, and through bond financing and innovative taxation schemes. It would act as a one-stop-shop for donors, coordinating funding of projects to many different PDPs.

"Do we need a super-PDP fund? Without a doubt," says Jean-François Alesandrini, a spokesman for the DNDi. However, he cautions that the details of the scheme still need fleshing out, particularly on the issue of attracting new donor funding. Many questions remain as to how the PDP+ Fund would work, adds Alesandrini, in particular its governance structure, and how its expert committees would choose which projects to fund.

Herrling says that informal discussions he has had with donors, including the US government, have been positive, as have those with other companies and groups that will be invited to come on board.

The PDP+Fund resembles the idea for a global research fund that was floated by a WHO expert panel in 2002 to complement the multibillion-dollar Global Fund to Fight AIDS, Tuberculosis and Malaria. This was created in the same year, but funds only disease-control measures, not research. The global research fund proposal never gained traction because governments considered it a risky venture, says Mary Moran, director of health policy at the George Institute. The difference now, says Herrling, is that PDPs are widely recognized to produce drug leads. "We have a state-of-the-art pipeline that now needs investment to take forward," he says.

Declan Butler 